\title{
Evaluation of Wheat genotypes on the basis of physiological indices under salt stress
}

\author{
Nazima Batool ${ }^{1 *}$, Noshin Ilyas ${ }^{1}$, Armghan Shahzad ${ }^{2}$, Muhammad \\ Arshad $^{1}$ and Fayyaz- Ul-Hassan ${ }^{3}$ \\ 1. Depertment of Botany, Pir Mehr Ali Shah Arid Agriculture University, Rawalpindi-Pakistan. \\ 2. National Institute for Genomics and Advanced Biotechnology, (NARC), Islamabad-Pakistan. \\ 3. Department of Agronomy, Pir Mehr Ali Shah Arid Agriculture University, Rawalpindi-Pakistan. \\ *Corresponding author's email: nazimabatool@gmail.com
}

Citation

Nazima Batool, Noshin Ilyas, Armghan Shahzad, Muhammad Arshad and Fayyaz- Ul-Hassan. Evaluation of Wheat genotypes on the basis of physiological indices under salt stress Pure and Applied Biology. Vol. 5, Issue 4, pp11831192. http://dx.doi.org/10.19045/bspab.2016.50142

\begin{tabular}{llll}
\hline \hline Received: 30/08/2016 & Revised: 28/09/2016 & Accepted: 13/10/2016 & Online First: 30/10/2016 \\
\hline \hline
\end{tabular}

Abstract

Salt stress is one of the major limitations for wheat plant growth and development. Screening of wheat cultivars for salt tolerance is an effective technique to identify tolerant cultivar for salt affected soil. In present study wheat genotypes (Pasban-90 and Frontana) were germinated in petri plates against control, $50 \mathrm{mM}, 75 \mathrm{mM}, 100 \mathrm{mM}, 125 \mathrm{mM}$ and $150 \mathrm{mM}$ salt levels and root \& shoot length, fresh \& dry weight, physiological indices like plant height stress indices (PHSI), plant fresh weight stress indices (PFSI), plant dry weight stress indices (PDSI), salt stress tolerance indices (STI), root toxicity (RT), shoot toxicity (ST) and germination energy (GE) were recorded for screening purpose. Root length (27\%), shoot length (48\%), fresh weight (47\%), dry weight (58\%), PHSI (38\%), PFSI (43\%), PDSI (40\%), GE (35\%) and SSTI (39\%) decreased with increasing salt levels. Correlation analysis of all observed traits shows highly positive correlation between PHSI, PFSI, PDSI, STI and GE while significant negative correlation with root and shoot toxicity. On the basis of morphological data and physiological indices Pasban-90 is categorized as a salt tolerant cultivar while Frontana as salt sensitive cultivar.

Keywords: Root length; Salt stress; Wheat; Fresh weight; Pasban-90

\section{Introduction}

Crop plants growth and productivity is considerably affected by different stresses such as water, salt, low temperature and high temperature stress. Salt stress is an important threat to wheat plant productivity and yield [1]. Salt stress is increasing day by day due to poor land practices and improper drainage [2]. About eight hundred Mha land in the world and six Mha area in Pakistan is affected due to salinity [3]. A high salt level causes ionic and osmotic impact on wheat crop; osmotic stress leads to disturbance in plant water relation and damages membrane stability [4]. High sodium in soil competes with potassium and calcium uptake and interrupts cellular ionic homeostasis [5]. Wheat is categorized as a major source of energy, grown throughout the world and wheat used as a staple food in Pakistan [3]. 
Pakistan is identified as a fourth in Asia and eleventh in world for wheat production [2]. Wheat plant yield drastically decrease with increasing $(100 \mathrm{mM}<)$ salt levels in soil [6]. Osmotic effect of stress negatively affects wheat seed germination and seedling growth [7]. Plant acquires tolerance mechanism to withstand salt stress condition and tolerance varies according to crop plant species. Wheat genotypes differ in their tolerance to high salt levels [8] and this information is useful for identification of tolerant cultivars for salt affected soils $[2,9]$. Many scientists has used physiological indices to identify tolerant cultivar at early stages $[3,7,10,11]$. This study was conducted to identify wheat cultivar that tolerate and survive under salt stress.

\section{Materials and methods}

The experiment was carried out at Marker Assisted Selection lab, NIGAB, National Agricultural Research Center, Pakistan. This study was carried out with complete randomized design (CRD) and three replication. Sodium hypochlorite solution was used for surface sterilization of seeds and for this purpose, seeds were dipped in $1 \%$ sodium hypochlorite solution for fifteen minutes then washed thoroughly with distilled water and placed in petri plates lined with filter paper. Seeds were germinated in normal condition or different salt levels (50mM, 75mM, 100mM, 125mM \& 150mM). Seed were considered germinated when radical length was $5 \mathrm{~mm}$
[4]. After 15 days of germination, seedling root and shoot length, fresh and dry weight was recorded and data was used to calculate following physiological indices $[3,4,12]$.

Salt stress tolerance indices $($ SSTI) $=$ stressed seedling promptness indices /control seedling promptness indices $\mathrm{x} 100$

Germination energy $=$ N/Tx 100

Where number of seedling over total days. Plant height stress indices $=$ stressed plant length /control plant length $\mathrm{x} 100$

Plant fresh weight stress indices $=$ stressed seedling fresh weight /control seedling fresh weight x 100

Plant dry weight stress indices $=$ stressed seedling dry weight /control seedling dry weight x 100

Shoot toxicity $=$ control plant shoot lengthstressed plant shoot length/control plant shoot lengthx 100

Root toxicity $=$ control plant root length stressed plant root length/control plant root length $\mathrm{x} 100$

\section{Results and discussion}

The salinity drastically reduces seed germination and significant variations were recorded between wheat genotypes and treatments $(\mathrm{P}<0.05) \quad$ (Figure 1). Wheat genotypes root length show slight changes with increasing salt levels. Root length decrease $16 \%, 18 \%, 21 \% 25 \%$ \& $27 \%$ at $50 \mathrm{mM}, \quad 75 \mathrm{mM}, 100 \mathrm{mM}, 125 \mathrm{mM}$ and $150 \mathrm{mM}$. Frontana show maximum reduction in root length (28\%) at $150 \mathrm{mM}$ salt stress. 


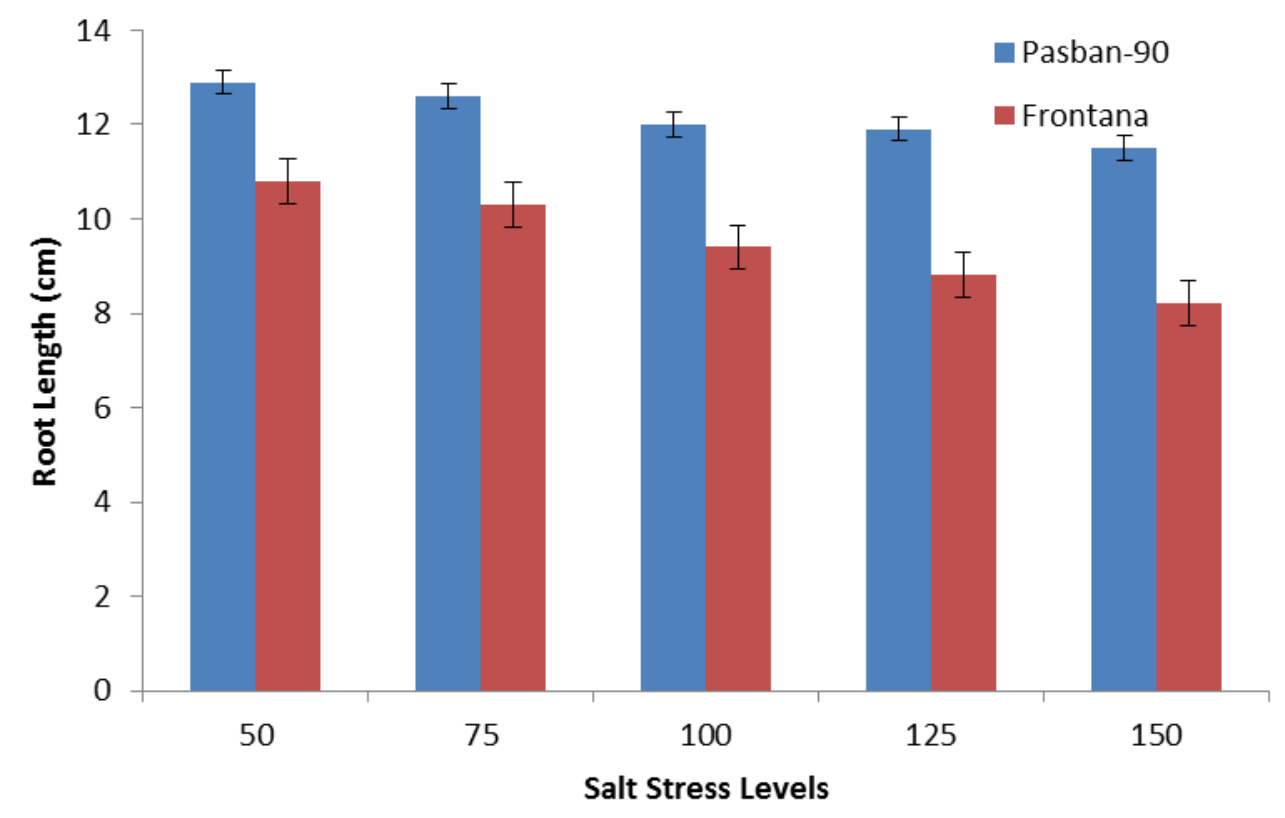

Figure 1. Root Length $(\mathrm{cm})$ of wheat cultivars under different salt levels

Shoot length of wheat genotypes considerable decrease and significant difference was observed between wheat genotypes and treatment $(\mathrm{P}<0.05)$ (Figure 2). Shoot length show maximum reduction at $100 \mathrm{mM}, 125 \mathrm{mM}$ and $150 \mathrm{mM}$ salt level and it was $20 \%, 31 \%$ and $40 \%$, respectively. Pasban 90 (5\%) and Frontana (12\%) show minimum reduction in shoot length at 50 $\mathrm{mM}$ while maximum reduction in shoot length $(52 \%)$ of Frontana was recorded at $150 \mathrm{mM}$.

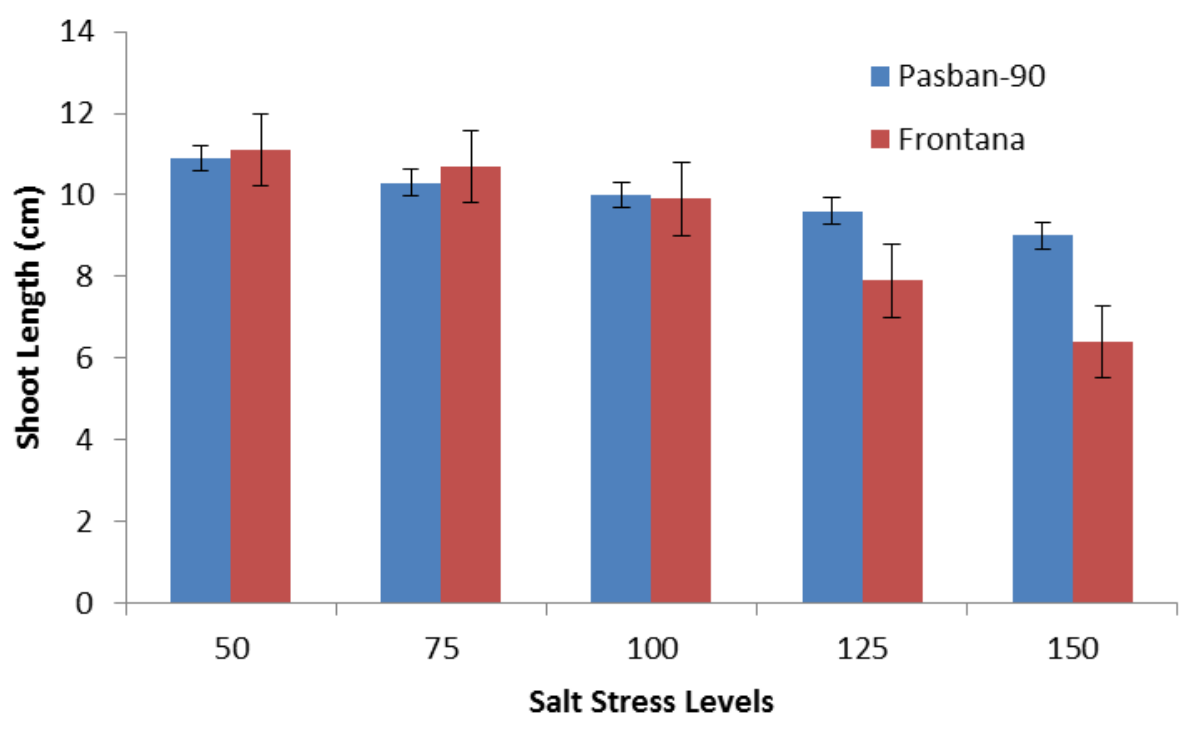

Figure 2. Shoot Length $(\mathrm{cm})$ of wheat cultivars under different salt levels.

Fresh and dry weight of wheat genotypes show significant reduction at higher salt levels (Figure 3 and 4). Fresh weight was decrease with increasing salt levels which were $10 \%, 12 \%, 18 \%, 24 \%$ \& $35 \%$ at $50 \mathrm{mM}, 75 \%, 100 \%, 125 \%$ and $150 \%$. 
Frontana show maximum reduction in dry weight $(64 \%)$ at $150 \mathrm{mM}$ salt stress while minimum reduction $(20 \%)$ was observed at $50 \mathrm{mM}$ salt levels. Wheat genotypes seed salt stress tolerance indices was decreased at 100 $\mathrm{mM}$ and higher salt levels. Salt stress tolerance indices (SSTI) was significantly decreased with increasing salt levels $(100 \mathrm{mM}, 125 \mathrm{mM}$ and $150 \mathrm{mM})$. Maximum salt stress tolerance indices was recorded for Pasban-90 (87.2\%) at 50mM salt level while minimum SSTI was observed for Frontana $(73 \%)$ at $50 \mathrm{mM}$. A Pasban-90 salt stress tolerance index was $70 \%$ at $100 \mathrm{mM}$ and $61 \%$ at $150 \mathrm{mM}$ though Frontana $(53 \%$ \& $39 \%$ ) demonstrates least SSTI value (Figure $5)$.

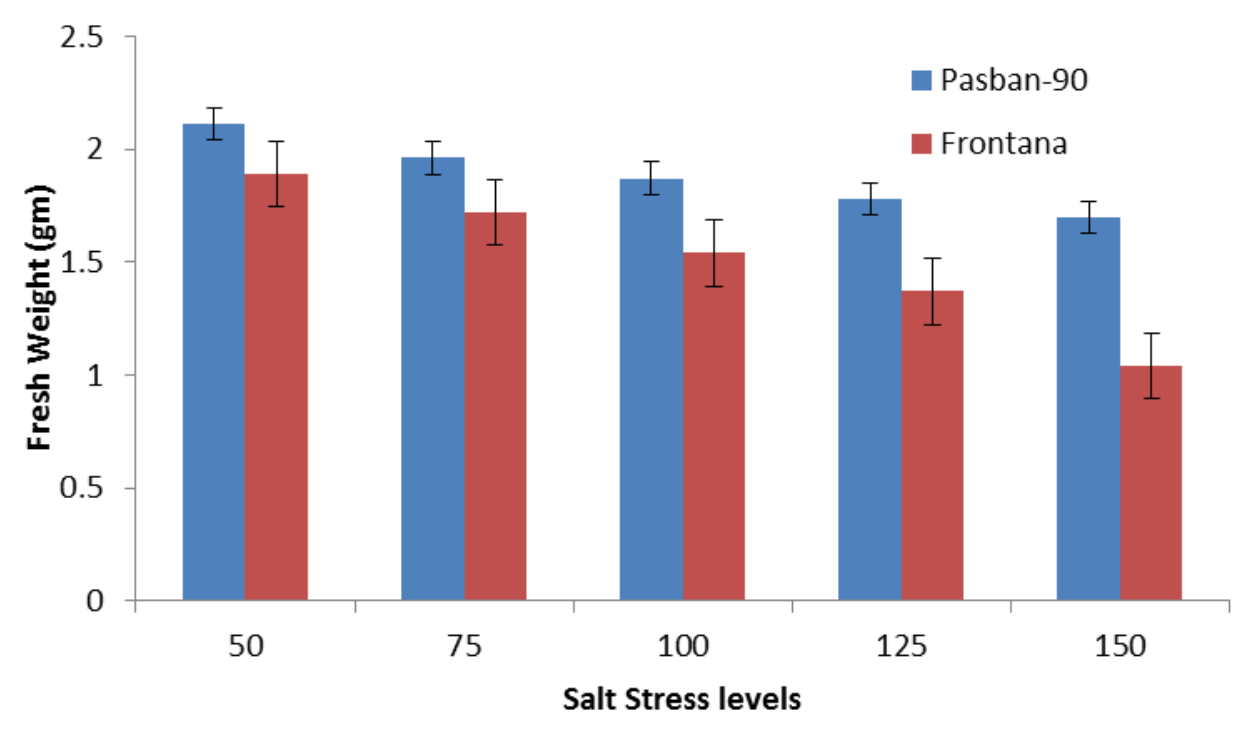

Figure 3. Fresh Weight (gm) of wheat cultivars under different salt levels

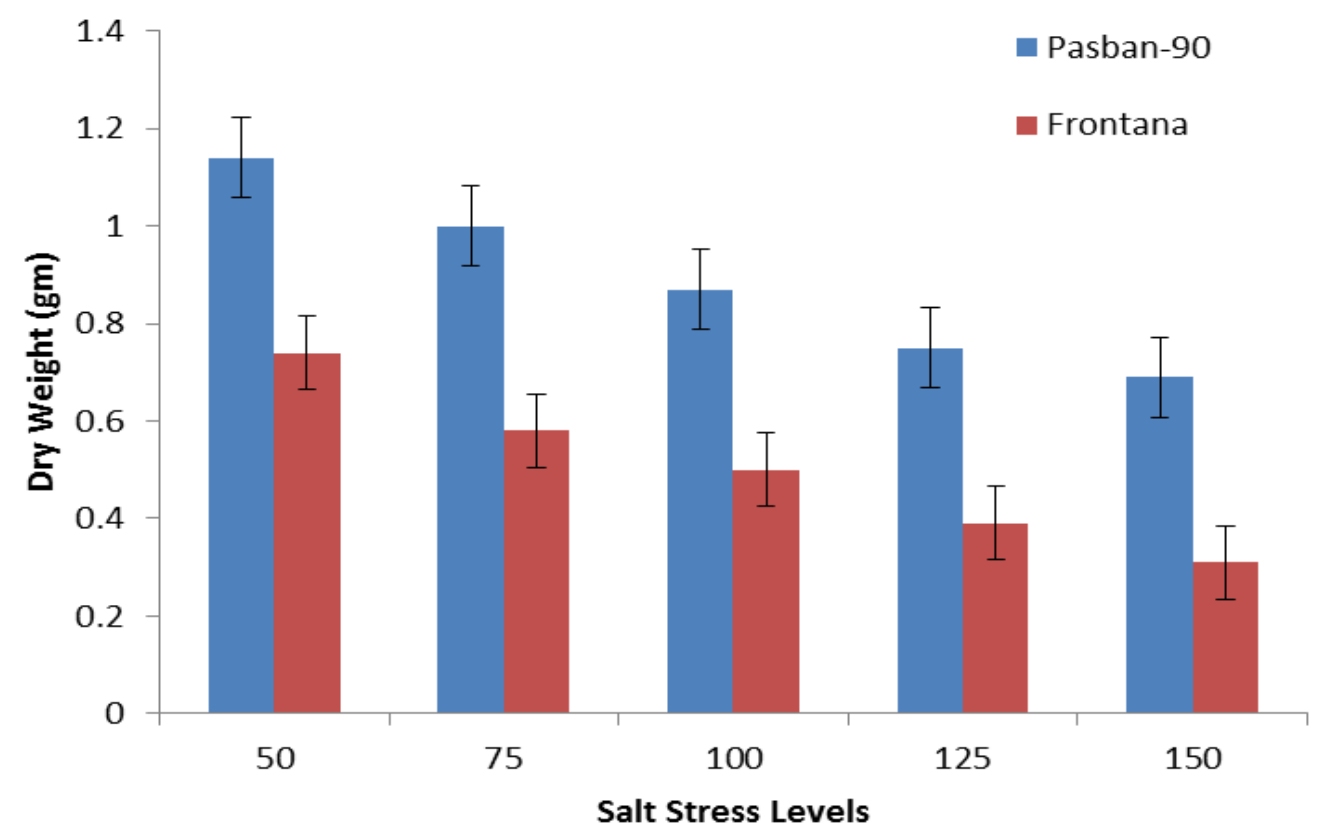

Figure 4. Dry Weight (gm) of wheat cultivars under different salt levels 


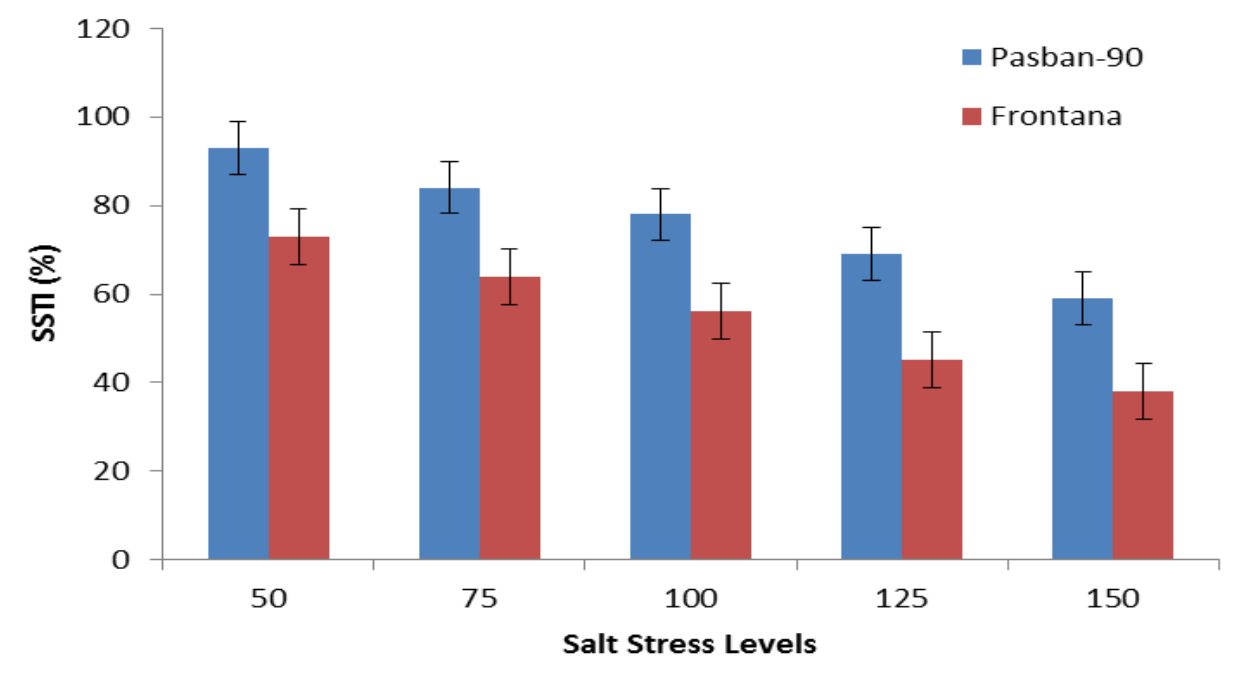

Figure 5. Salt stress tolerance indices $(\%)$ of wheat cultivars under different salt levels

Germination energy (GE) was recorded on the basis of number of seedling emerged and total days of germination (Figure 6). Germination energy was decreased with increasing salt levels and it was $45 \%$ at $100 \mathrm{mM}, 40 \%$ at $125 \mathrm{mM}$ and $33 \%$ at 150mM. Pasban-90 (62\%) show maximum germination energy at $50 \mathrm{mM}$ salt level while minimum GE was observed for Frontana (50\%). Similarly, Seedling Root length, shoot length, gerimination percentage, mean daily germination rate, seedling fresh weight and seedling dry weight considerably reduces under salt stress. Hussain et al. [9] finding show that wheat seed germination is interrupted due to increasing salt levels [12, 13]. Wheat seed germination delay due to osmotic effect or ionic effect salinity [14, 15] and osmotic effect alters plant water relations and excessive accumulation of $\mathrm{Na}^{+}$ or $\mathrm{Cl}^{-}$ions disturbs physiological processes $[3,16]$.

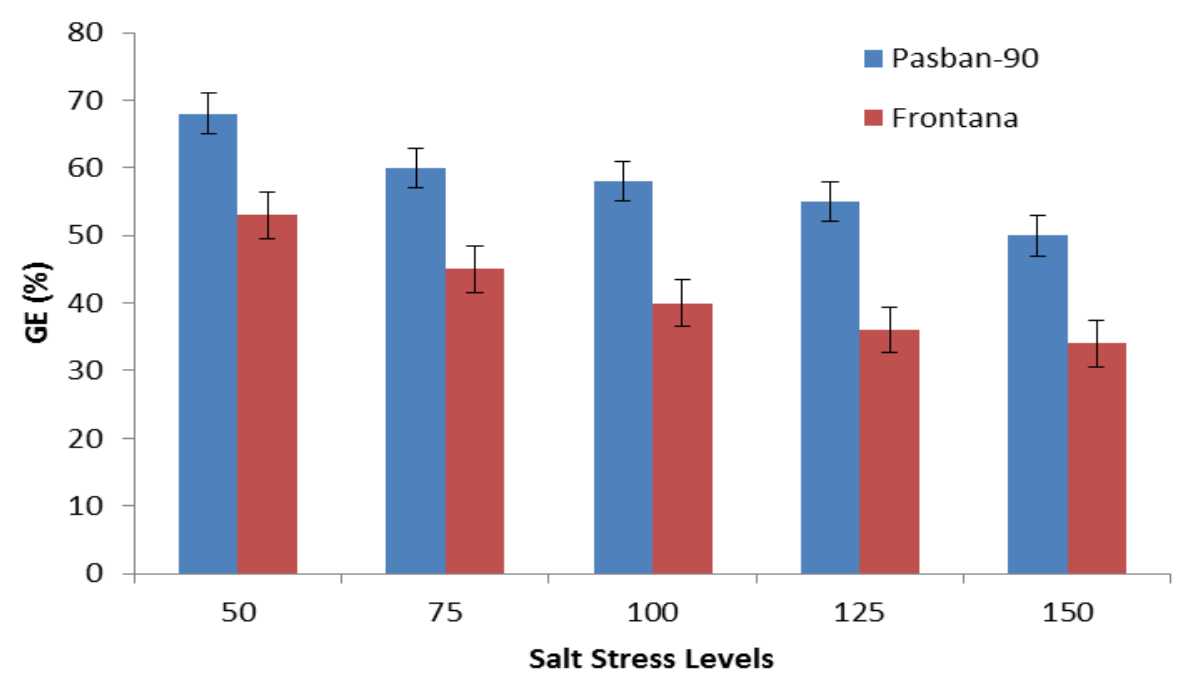

Figure 6. Germination energy (\%) of wheat cultivars under different salt levels 
Wheat plant growth and development showed decrease under higher salt levels. Plant height stress index was decreased with increasing salt levels which were $80 \%, 75 \%$, $70 \%, 62 \%, 54 \%$ at different salt levels (Figure 7). Maximum plant height stress indices was observed for Pasban-90 (71\%) at $50 \mathrm{mM}$ while Frontana (59.8\%) show minimum plant height stress indices at 50 $\mathrm{mM}$ salt level. Pasban-90 shows plant height stress indices $70 \%$ at $75 \mathrm{mM}, 63 \%$ at $100 \mathrm{mM}, 54 \%$ at $125 \mathrm{mM}$ and $50 \%$ at $150 \mathrm{mM}$ while Frontana show least PHSI value it was $39.7 \%$ at $100 \mathrm{mM}$ and $31.8 \%$ at $150 \mathrm{mM}$.

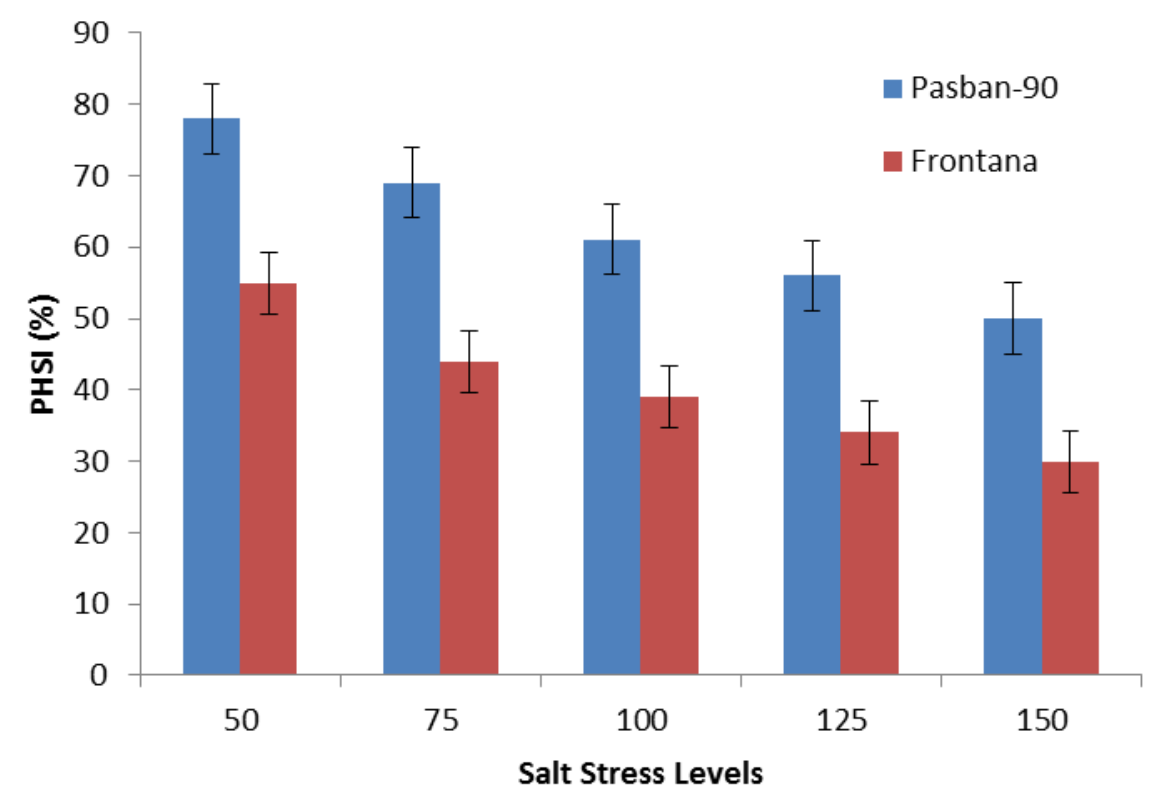

Figure 7. Plant height stress indices of wheat cultivars under different salt levels

Plant fresh and dry weight showed significant reduction under different salt levels $(\mathrm{P}<0.05)$ (Figure 8 and 9). Plant fresh weight stress indices (PFSI) and plant dry weight stress indices (PDSI) considerably decreased with increasing salt stress. PFSI reduction was recorded with increasing salt levels and which were $63 \%, 59 \%, 52 \% 50 \%$ and $44 \%$ with increasing salt levels, respectively. PFSI minimum value recorded for Frontana (59.8\%) while maximum plant fresh weight stress tolerance indices was observed for Pasban-90 (68\%) at 50mM. A plant dry weight stress tolerance indices was affected due to salinity $(\mathrm{P}<0.05)$ and show reduction $60 \%, 57 \%, 52 \%, 49 \%, 45 \%$ and $40 \%$ at $50 \mathrm{mM}, 75 \mathrm{mM}, 100 \mathrm{mM}, 125 \mathrm{mM}$ and
150mM sodium chloride levels. Maximum PDSI was observed for Pasban-90 (62\%) at $50 \mathrm{mM}$ while Frontana demonstrates poor PDSI at 100 and $150 \mathrm{mM}$ salt levels. Likewise, Kausar et al. [11] findings identified that salt stress considerable decrease all physiological indices in which include root length, shoot length, fresh weight and dry weight. Salt stress damage seedling cell membrane as a result sodium ion competes with calcium and potassium ion [17]. Ion homeostasis disturbance significantly decreaseseedling growth and development [18]. Basalah [19] was recorded considerable decrease in wheat plant fresh and dry weight under salt stress [20]. 


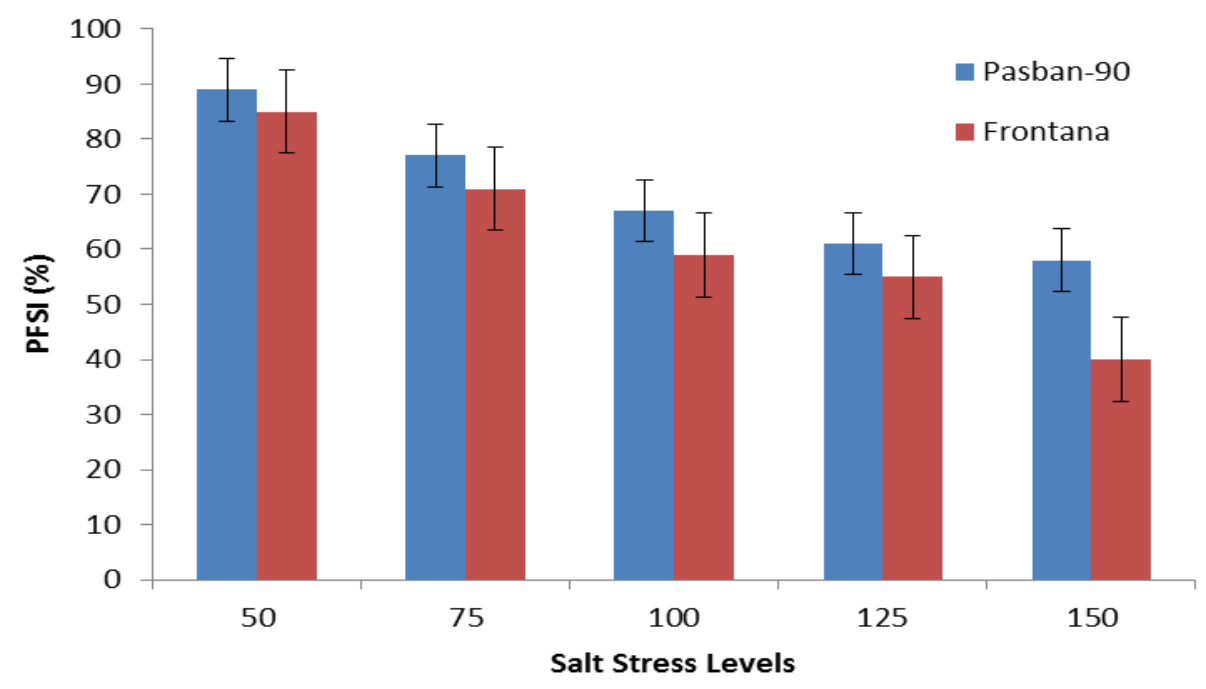

Figure 8. Plant fresh weight stress indices of wheat cultivars under different salt levels

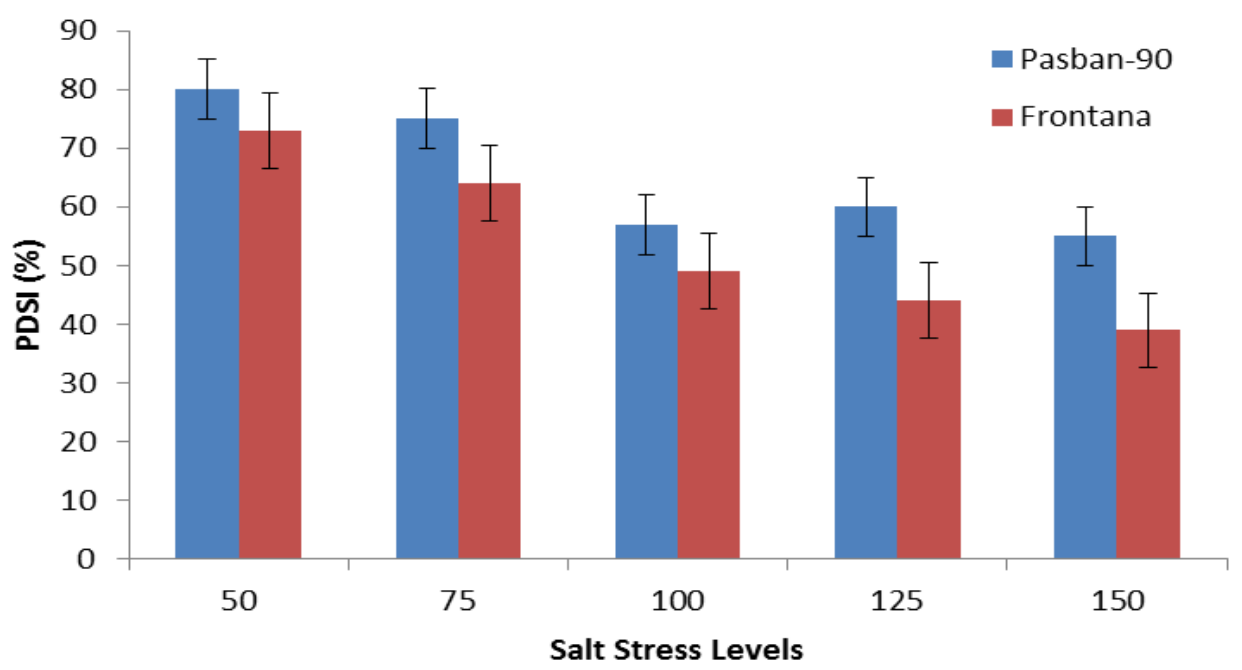

Figure 9. Plant dry weight stress indices of wheat cultivars under different salt levels

Shoot length show reduction with gradual increase in salt levels. Wheat genotypes shoot toxicity significantly enhanced under salt stress $(\mathrm{P}<0.05)$ (Figure 10). Maximum shoot toxicity was recorded for Frontana $(57 \%)$ at $150 \mathrm{mM}$ salt levels whereas minimum shoot toxicity was shown by Pasban-90 (39\%). Shoot toxicity increase with increasing salt stress. Root toxicity was showed significant difference among wheat genotypes and salt treatments $(\mathrm{P}<0.05)$ (Figure 11). Root toxicity increased with increasing salt levels and maximum root toxicity was observed for Frontana (48\%) at $150 \mathrm{mM}$ salt levels while least toxicity was observed for Pasban-90 (35\%). Root and shoot length decreased with increase of salt levels [7, 21]. Similar findings by Akhter $e t$ al. [23], they reported that when wheat genotypes exposed to higher salt levels this induce ion toxicity and decrease shoot growth [24] and this ion toxicity interfere with uptake of ions from soil $[2,25]$. 


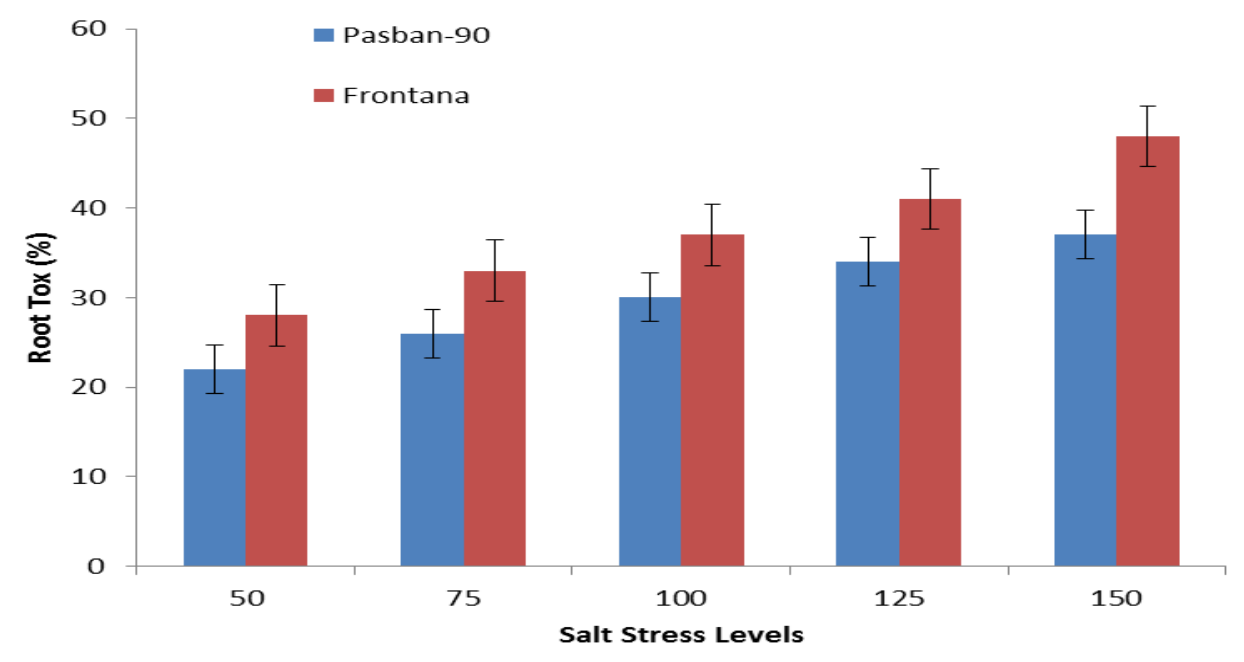

Figure 10. Shoot toxicity (\%) of wheat cultivars under different salt levels

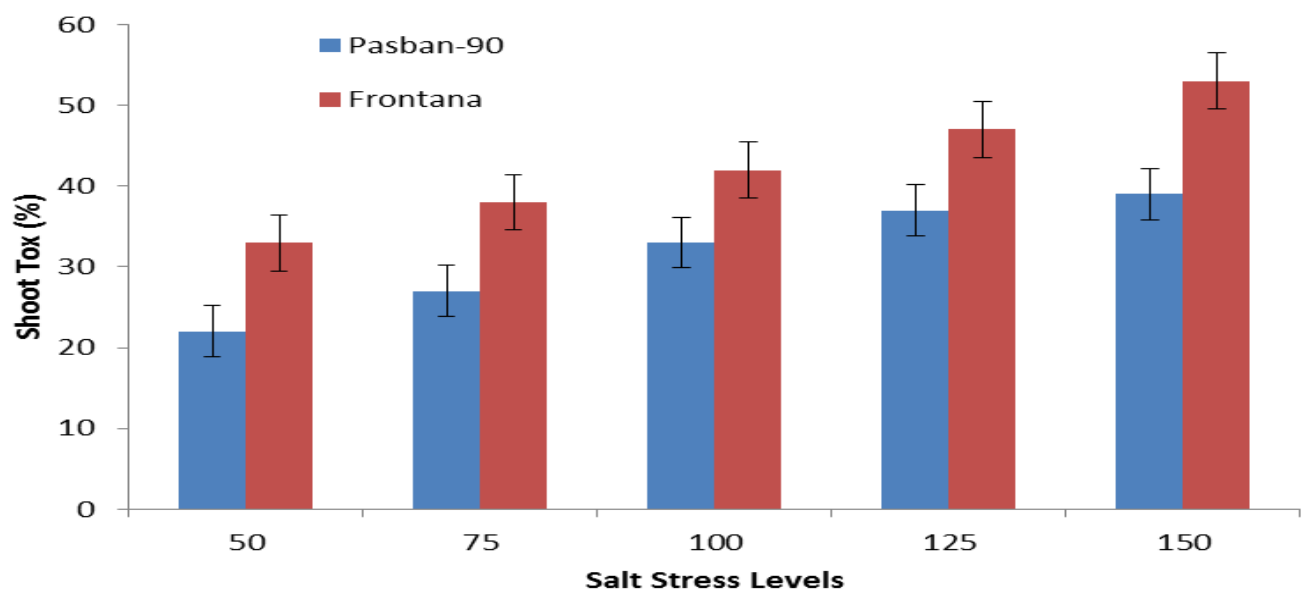

Figure 11. Root toxicity (\%) of wheat cultivars under different salt levels

Correlation analyses were done for PHSI, PFSI, PDSI, SSTI, GE, shoot toxicity and root toxicity (Table 1). The significant positive correlation was observed between PHSI, PFSI, PDSI, SSTI and GE while a very strong negative correlation were recorded for root and shoot toxicity. Shoot and root toxicity negatively correlated with PHSI $\quad(\mathrm{r}=0.895, \quad \mathrm{r}=0.77, \quad \mathrm{P}<0.05)$, PFSI $(\mathrm{r}=0.801, \quad \mathrm{r}=0.92, \quad \mathrm{P}<0.05), \quad$ PDSI $(\mathrm{r}=0.78, \mathrm{r}=0.84, \mathrm{P}<0.05)$, SSTI $(\mathrm{r}=0.802$, $\mathrm{r}=0.82, \mathrm{P}<0.05)$ and $\mathrm{GE}(\mathrm{r}=0.737, \mathrm{r}=0.68$, $\mathrm{P}<0.05)$ though positive correlation was observed among root and shoot toxicity.
Plant fresh weight show highly positive correlation with PDSI $(\mathrm{r}=0.911, \mathrm{P}<0.01)$ and PHSI $\quad(r=0.933, \quad \mathrm{P}<0.01)$ while positive correlation with SSTI $(\mathrm{r}=0.84, \mathrm{P}<0.05)$ and GE $(\mathrm{r}=0.69, \quad \mathrm{P}<0.05)$. Similar correlation trend was observed Kausar et al. [11] in which they find that germination stress tolerance indices were positively correlated with plant length stress indices [26, 27]. SSTI was an effective tool for screening of salt tolerant wheat genotypes [28]. Positive correlation in PHSI, PFSI, PDSI, SSTI and GE show that physiological indices can be used as a screening tool. 
Table 1.Correlation Coefficient analysis of Germination attributes for wheat cultivars

\begin{tabular}{|l|l|l|l|l|l|l|l|}
\hline & PHSI & PFSI & PDSI & SSTI & GE & Shoot Tox & Root Tox \\
\hline PHSI & 1 & & & & & & \\
\hline PFSI & $0.933^{*}$ & 1 & & & & & \\
\hline PDSI & $0.856^{*}$ & $0.911^{*}$ & 1 & & & & \\
\hline SSTI & $0.961^{*}$ & $0.843^{*}$ & $0.972^{*}$ & 1 & & & \\
\hline GE & $0.819^{*}$ & $0.698^{*}$ & $0.733^{*}$ & $0.827^{*}$ & 1 & & \\
\hline Shoot Tox & $-0.895^{*}$ & $-0.80^{*}$ & $-0.78^{*}$ & $-0.801^{*}$ & $-0.737^{*}$ & 1 & \\
\hline Root Tox & $-0.77^{*}$ & $-0.92^{*}$ & $-0.84^{*}$ & $-0.828^{*}$ & $-0.681^{*}$ & $0.869^{*}$ & 1 \\
\hline
\end{tabular}

Significance levels: ${ }^{*} \mathrm{P}=0.05, * * \mathrm{P}=0.01$, ${ }^{\mathrm{ns}}$ non-significant; PFSI: plant height stress index, PFSI: plant fresh weight stress index. PDSI: plant dry weight stress index, SSTI: seedlings stress tolerance index, GE: Germination Energy, Shoot Tox: Shoot Toxicity, Root Tox: Root Toxicity

\section{Authors' contributions}

Conceived and designed the experiments: $\mathrm{N}$ Batool, N Ilyas \& A Shahzad, Performed the experiments: N Batool, Analyzed the data: $\mathrm{N}$ Batool, Contributed reagents/ materials/ analysis tools: N Ilyas, A Shahzad, M Arshad \& FU Hassan, Wrote the paper: N Batool, N Ilyas \& A Shahzad.

\section{References}

1. Khan MA, Yasmin S, Ansari R, Shirazi MU \& Ashraf (2007). Screening for salt tolerance in wheat genotypes at an early seedling stage. Pak J Bot 39: 25012509

2. Ahmad M, Armghan S, Muhammad I, Muhammad A \& Arvind HH (2013). Morphological and molecular genetic variation in wheat for salinity tolerance at germination and early seedling stage. Aust J Crop Sci 7(1): 66-74.

3. Zafar SA, Shokat S, Ahmed HGMD, Khan A, Ali MZ \& Rana MA (2015). Assessment of salinity tolerance in rice using seedling based morphophysiological indices. Adv life Sci 2(4): 142-149.

4. Mirza SR, Ilyas N \& Batool N (2015). Seed priming enhanced seed germination traits of wheat under water, salt and heat stress. Pure Appli Biol 4(4): 650-658. http://dx.doi.org/10.19045/bspab.2015. 44025.

5. Munns R \& Tester M(2008). Mechanisms of salinity tolerance. Ann Rev Plant Bio 59: 651-681.

6. Mehmet A, Kaya MD \& Kaya G (2006). Effects of $\mathrm{NaCl}$ on the germination, seedling growth and water uptake of triticale. Turk J Agrie Forestry 30: 3947.

7. Hussain S, Abdul K, Amar M, Muhammad AW \& Irfan A (2013). Germination and growth response of three wheat cultivars to $\mathrm{NaCl}$ salinity. Soil Environ 32(1): 36-43.

8. Hakim AM, Juraimi AS, Begum M, Hanafi MM, Ismail MR \& Selamat A (2010). Effect of salt stress on germination and early seedling growth of rice (Oryza sativa L.).Afr. J Biotech 9(13): 1911-1918.

9. Hussain M, Muhammad AK, Mumtaz H, Nazir J \& Ihsan K (2015). Application of Phenotypic and Molecular Markers to Combine Genes for Durable Resistance against Rust Virulences and High Yield Potential in Wheat. Int $J$ Agric Biol 17(3): 421-430.

10. Kaya C, Tuna AL \& Yokas I (2009). The role of plant hormones in plants under salinity stress. Book sal. Water Stress 44: 45-50.

11. Kausar A, Ashraf MY, Ali I, Niaz M \& Abbass Q (2012). Evaluation of sorghum varieties/lines for salt tolerance using physiological indices 
as screening tool. Pak J Bot 44(1): 4752.

12. Ashraf MY, Hussain F, Akhtar J, Gul A, Ross M \& Ebert G (2008). Effect of different sources and rates of nitrogen and supra optimal level of potassium fertilization on growth, yield and nutrient. Pak J Bot 40(4): 1521-1531.

13. Afzal I, Butt A, Rehman H, Basra SMA \& Afzal A (2012). Alleviation of salt stress in fine aromatic rice by seed priming. Aust J Crop Sci 6: 14011407.

14. Farooq M, Habib M, Rehman A, Wahid A \& Munir R (2011). Employing aqueous allelopathic extracts of sunflower in improving salinity tolerance of rice. J Agri and Social Sci 7: 75-80.

15. Farshadfar E \& Elyasi P (2012). Screening quantitative indicators of drought tolerance in bread wheat (Triticum aestivum L.) landraces. Euro J. ExpBiol 2: 577-584.

16. Farooq M, Basra SMA, Hafeez K \& Ahmad N (2005). Thermal hardening: A new seed vigor enhancing tool in rice. J Integrative Plant Biol 47: 187193.

17. Takel A (2000). Seedling emergence and growth of sorghum genotypes under variable soil moisture deficit. Agron J 48: 95-102.

18. Rejili M, Vadel MA, Guetet A, Mahdhi M, Lachiheb B, Ferchichi A \& Mars M (2010). Influence of temperature and salinity on the germination of Lotus creticus (L.) from the arid land of Tunisia. Afr J Eco 48: 329-337.

19. Basalah MO (2010). Action of salinity on seed germination and seedling growth of Solanum melongena L. $J$ Agri Res Kafer El-Sheikh Uni 36: 6473.
20. Almodares A, Hadi MR \& Dosti $\mathrm{B}(2007)$. Effects of salt stress on germination percentage and seedling growth in sweet sorghum cultivars. $J$ Biol Sci 7: 1492-1495.

21. EL-Hendawy SE, Ruan Y, Hu Y \& Schmidhalter U (2009). A Comparison of Screening Criteria for Salt Tolerance in Wheat under Field and Controlled Environmental Conditions. J Agro Crop Sci 195: 356-367.

22. Akhtar M, Hussain F, Ashraf MY, Qureshi TM, Akhter J \& Awan AR(2012). Influence of salinity on nitrogen transformations in soil. Comm Soil Sci Plant Ana 43: 1674-1683.

23. Ashraf MY, Rafique N, Ashraf M, Azhar N \& Marchand M (2013). Effect of supplemental potassium $(\mathrm{K}+)$ on growth, physiological and biochemical attributes of wheat grown under saline conditions.J Plant Nutr 36: 443-458. http://dx.doi.org/10.1080/01904167.20 12.748065

24. Asgaria HR, Cornelisb W \& VanDamme P (2012). Salt stress effect on wheat (Triticum aestivum L.) growth and leaf ion concentrations. Inter $J$ Plant Prod 6 (2): 1735-8043.

25. Akbarimoghaddam H, Galavi M, Ghanbari A \& Panjehke N(2011). Salinity effects on seed germination and seedling growth of bread wheat cultivars. Trak J Sci 9(1): 43-50.

26. Saboora A \& Kiarostami K (2006). Salinity tolerance of wheat genotype at germination and early seedling growth. Pak J Biol Sci 9: 2009-2021.

27. Ali Y, Islam Z, Ashraf MY \& Tahir GR (2004). Effect of salinity on chlorophyll concentration, leaf area, yield and yield components of rice genotypes grown under saline environment. Inter JEnv Sciand Tech 3: 221-225. 